\title{
Strain-ageing effects on the residual low-cycle fatigue life of low-carbon steel reinforcement
}

\author{
Giuseppe Loporcaro $($ ) Alberto Cuevas · Stefano Pampanin · Milo V. Kral
}

Received: 24 September 2020/ Accepted: 6 January 2022/Published online: 22 January 2022

(C) The Author(s) 2022

\begin{abstract}
Low-cycle fatigue (LCF) failures can be expected when rebars are subjected to a small number of cycles at large stress/strain amplitudes. Major seismic events are often preceded or followed by other events of smaller/larger magnitude. During each event, the residual fatigue life of the steel reinforcement may reduce, eventually leading to failure of the bars due to the cumulative damage. Strain ageing may reduce even more the residual fatigue life of steel. This paper presents the results of an experimental testing campaign conducted on samples fabricated from New Zealand Grade 300E steel. A benchmark LCF life was obtained for 12-mm steel reinforcing bars subjected to
\end{abstract}

\section{G. Loporcaro $(\bowtie)$}

Department of Civil and Natural Resources Engineering, University of Canterbury, 20 Kirkwood Avenue, Upper Riccarton, Christchurch 8042, New Zealand

e-mail: giuseppe.loporcaro@ canterbury.ac.nz

\section{A. Cuevas}

Thornton Tomasetti Inc., Los Angeles,

CA, USA

\section{S. Pampanin}

La Sapienza University of Rome, Rome, Italy

e-mail: stefano.pampanin@uniroma1.it

\section{S. Pampanin}

University of Canterbury, Christchurch, New Zealand

M. V. Kral

Department of Mechanical Engineering, University of

Canterbury, Christchurch, New Zealand axial-strain-controlled completely reversed cyclic tests at amplitudes ranging between 0.78 and $2.75 \%$. The reduction in fatigue life attributed to strain ageing was obtained by comparing the benchmark fatigue life with that of steel reinforcing bars precycled up to $33 \%$ and $66 \%$ of the benchmark life and artificially strain aged for an equivalent period of 1 year at $15^{\circ} \mathrm{C}$. The Coffin-Manson and Koh-Stephens models were employed to evaluate the experimental results. The study demonstrates that, depending on the strain amplitude, strain ageing can cause a reduction in total and residual fatigue life ranging from 20 to $70 \%$. Strain ageing should not be ignored during the assessment of earthquake-damaged steel reinforcing bars.

Keywords Low-cycle fatigue - Reinforcing steel · Strain ageing $\cdot$ Steel mechanical properties $\cdot$ Seismic assessment

\section{Introduction}

During earthquakes, steel reinforcing bars (rebars) embedded in reinforced concrete members may undergo a small number of cycles at large inelastic amplitude in tension and compression as high as $6 \%$ strain, eventually fracturing the rebars due to a mechanism known as low-cycle fatigue (LCF) [1]. 
The cyclic stress and strain induced by the seismic event may cause microscopic physical damage to the steel reinforcement. As the number of cycles increases, the microscopic damage accumulates and generates a crack that will eventually cause the material to fracture. This failure mode was recorded during experimental tests on circular bridge columns $[2,3]$. LCF fracture of buckled rebars was also observed in bridge piers during the $2016 \mathrm{Mw} 7.8$ Kaikoura earthquake in New Zealand (Fig. 1) [4].

Seismic events may be preceded and/or succeeded by foreshocks and aftershocks, numerous months apart. Fracture of reinforcing bars may not take place in an initial single seismic event, but in a successive one caused by the cumulative damage. If the steel reinforcing bars yield in a seismic event, strain ageing is likely to occur in susceptible steels, which causes a change in the mechanical properties of the materials [5].

\section{Literature review}

\subsection{Strain ageing}

Plastically deformed low-carbon steel may experience strain ageing. This is a time- and temperature-dependent phenomenon that produces the reappearance of the discontinuous yielding point, an increase in yield and total tensile stress, and a reduction in total strain. Strain ageing is produced by the diffusion of

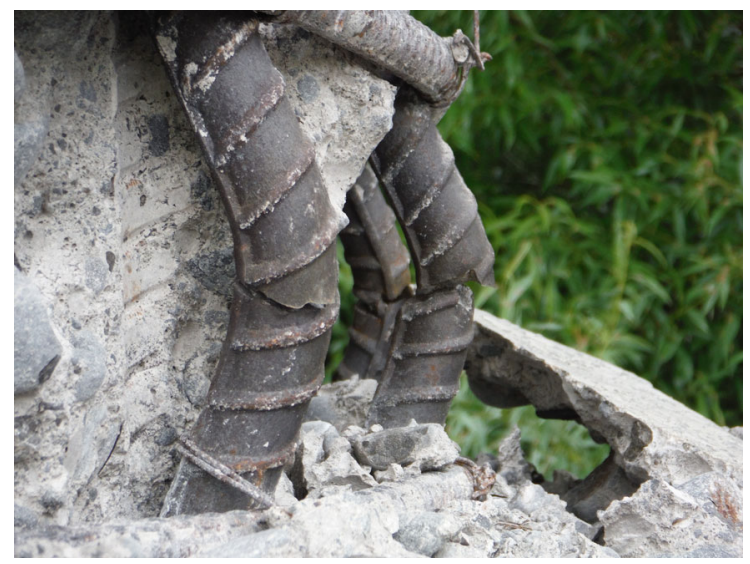

Fig. 1 Fractured longitudinal reinforcing bars in a bridge column located near the epicentre of the 2016 Kaikoura earthquake interstitial nitrogen and carbon atoms within the dislocation sites formed during plastic deformation. Carbon and nitrogen atoms create a "pinning" effect that reduces the mobility of the dislocation. This pinning effect becomes stronger with the interstitial content of nitrogen and carbon, and ageing time [6]. The effect of strain ageing on the mechanical properties of steel reinforcing bars has been investigated by a number of researchers [5, 7, 8]. More recently, Loporcaro et al. [5] quantified the increase in yield strength due to strain ageing in New Zealand-manufactured Grade 300E steel reinforcing bars. The study demonstrated that strain ageing, at ambient temperatures, is common on lower yield strength steels (e.g. Grade 300E). On the other hand, New Zealand Grade 500E Micro-alloyed (MA) is produced with the addition of $0.08 \%$ to $0.10 \%$ by mass of vanadium. Vanadium increases the steel strength as well as eliminates the effects of strain ageing at temperatures up to $150{ }^{\circ} \mathrm{C}[5,9]$.

\subsection{Low-cycle fatigue models}

Low-cycle fatigue analyses are performed by using the strain-based approach. This approach assumes that plastic yielding occurs in localised regions of the material, where fatigue cracks will eventually develop. The fatigue life estimation of structural materials is conducted by adopting strain-fatigue life curves. Fatigue lives are obtained experimentally through completely reverse strain-controlled tests in which the strain amplitude is maintained constant [10]. Experimental results are plotted on log-log coordinates graphs. The number of cycles to failure $\left(N_{f}\right)$ or half-cycle $\left(2 N_{f}\right)$ is represented on the $\mathrm{x}$-axis, while the strain amplitude $\left(\varepsilon_{a}\right)$ on the y-axis. The strain amplitude $\left(\varepsilon_{a}\right)$ is made up of an elastic $\left(\varepsilon_{e a}\right)$ and plastic part $\left(\varepsilon_{p a}\right)$.

Numerous models are available in the literature to predict the low-cycle fatigue life of materials. The Basquin relationship [11] combined with the CoffinManson model, developed separately in the late 1950s by Coffin [12] and Manson [13], is the most common. From this model, the number of cycles to failure $N_{f}$, for a given strain amplitude $\varepsilon_{a}$ can be estimated.

$\varepsilon_{a}=\frac{\sigma_{f}^{\prime}}{E}\left(2 N_{f}\right)^{b}+\varepsilon_{f}\left(2 N_{f}\right)^{c}$ 
The first term of Eq. (1) $\left(\frac{\sigma_{f}^{\prime}}{E}\left(2 N_{f}\right)^{b}\right)$ corresponds to the elastic strain amplitude which was developed by Basquin [11], meanwhile the second term $\left(\varepsilon_{f}\left(2 N_{f}\right)^{c}\right)$ corresponds to the plastic strain amplitude. The constants $\sigma_{f}$ (fatigue strength coefficient), $b$ (fatigue strength exponent), $\varepsilon_{f}$ (fatigue ductility coefficient), $c$ (fatigue ductility exponent) are material dependent. The coefficients correspond to the intercepts, while the exponents correspond to the slopes of the linear regression fit of the elastic and plastic experimental data (strain amplitude versus $2 N_{f}$ ) on a double logarithmic scale [14]. $E$ is the material elastic modulus.

Koh and Stephens [15] provided an alternative model to the Coffin-Manson model. They observed that the Coffin-Mason model did not provide conservative predictions for shorter lives (below 50 cycles). The Koh and Stephens model relates the fatigue life $N_{f}$, to the total strain amplitude $\varepsilon_{a}$ :

$\varepsilon_{a}=M\left(2 N_{f}\right)^{m}$

The constants $M$ (fatigue ductility coefficient) and $m$ (fatigue ductility exponent) are material dependent. The coefficient $M$ is the intercept, while $m$ is the slope of the linear regression fit of the total strain amplitude versus $N_{f}$ experimental data on a double logarithmic scale.

\subsection{Experimental work on the low-cycle fatigue of steel reinforcing bars}

Experimental research on the LCF properties of steel reinforcing bars has been conducted over the years. Mander et al. [1] tested ASTM A615 grade 40 $\left(f_{y}=276 \mathrm{MPa}\right)$ ordinary deformed steel reinforcing bars and ASTM A722 $\left(f_{y}=1083 \mathrm{MPa}\right)$ high strength threaded bars. Reinforcing bars were subjected to cyclic-strain amplitudes ranging from yield to $6 \%$ strain. The fatigue lives experimentally obtained were used to calibrate the Coffin-Manson, Koh-Stephens, Modified SWT (Smith, Watson, and Topper), Lorenzo-Laird and the energy-based models. Strain-life fatigue curves were developed. The steel samples were tested unmachined in order to capture the bars' inelastic buckling. A custom-built extensometer was used to measure the axial strain over the gauge length of the central three-bar diameters. The extremes of the extensometer gauge length corresponded to the expected inflection points of a double curvature buckled specimen. Therefore, the extensometer was expected to measure an average strain along the buckled length of the specimen. Cyclic hardening was observed in the A615 grade 40 ordinary steel, while cycle softening was observed in the A722 high strength pre-stressing thread bars. Then, after a few cycles, a stable behaviour was reached; this continued until cracking began and the stress at reversal dropped rapidly until complete fracture. The cycle when the stress-drop at reversal started was considered the failure cycle. This method was used to identify the fatigue life $\left(N_{f}\right)$ for samples tested at amplitudes smaller than $0.02 \mathrm{~mm} / \mathrm{mm}$. At larger strain amplitude, $N_{f}$ was determined visually. Restrepo-Posada and Dodd [16] conducted a series of tests on New Zealand Grade $300\left(f_{y}=300 \mathrm{MPa}\right)$ and Grade $430\left(f_{y-}\right.$ $=430 \mathrm{MPa}$ ) reinforcing bars in order to observe the effects of variables such as bar deformations, strain rate and strain ageing on the cyclic behaviour. They observed that, provided that buckling was precluded, the deformations did not affect the cyclic behaviour (in terms of hysteresis loop shape) of the rebars. Instead, an increase in strain rate caused an increase in upper and lower yield strength, ultimate tensile strength, and also strain at the onset of strain hardening. The effects of natural strain ageing (37 and 147 ageing days) were observed in terms of an increase in yield strength when the bars were pre-strained monotonically or cyclically. The increase in yield strength was observed only in Grade 300 and not in Grade 430. LCF life of reinforcing steel bars (ASTM Grade 60 reinforcement, $f_{y}$ ranging from 655 to $725 \mathrm{MPa}$ ) was also investigated by Brown and Kunnath [17]. Reinforcing bars were tested under a constant amplitude, cyclic strain regime, then strain and energy models were employed to predict low-cycle fatigue life. A special test set-up was constructed to transfer the required axial force to plastically deformed bars up to $25.4 \mathrm{~mm}$ (1 inch) diameter. The comparison between the analytical and experimental results showed that the Coffin-Manson and Koh-Stephens models gave more accurate results than the energy-based models [17]. Hawileh et al. [18] conducted displacement-controlled cyclic tests on bars produced to British Standards. BS460B and BS500B unmachined bar samples were tested at different strain amplitudes ranging from 3 to $10 \%$, and varying the strain ratio $(\mathrm{R}=1,0.5$ and 0$)$. The experimental results showed that both the Coffin- 
Masons and the Koh-Stephens models can be employed to accurately predict the fatigue life of BS460B and BS500B bars. Moreover, it was observed that the fatigue life prediction based on the total strain amplitude was more accurate than the prediction based only on the plastic strain amplitude. Hawileh et al. [19] performed strain-controlled cyclic tests on unmachined ASTM A706 and A615 Grade 60 reinforcing steel bars. Buckling was prevented by using a steel collar that surrounded the bars during the test. The experiments aimed to quantify the low-cycle fatigue life of damping mild steel rebars that are typically used in precast seismic structural systems (PRESSS). The rebars were subjected to peak strain that ranged between 2 and $8 \%$. It was observed that the fatigue life of A706 and A615 was comparable, even though A706 bars had a larger monotic ductility. The model proposed by Koh-Stephens [15] best represented the experimental data when the total strain was considered. On the other hand, the model proposed by Mander et al. [1] best represented the experimental results when only the plastic strain amplitude was considered. Hawileh et al. [20] conducted LCF experimental tests on seven steel bars types. Correlations between fatigue life and chemical composition were assessed. The elements with the highest negative correlations were chromium, silicon and manganese. Energy-based models were developed by Abdalla et al. [21] to predict the low-cycle fatigue life of BS460B and BS500B steel reinforcing bars. The models were based on the energy dissipated on the first cycle, on the average cycles (from the second to the fifth) and on the total energy dissipated to failure. It was also observed that BS500B steel dissipated more energy than BS460B, making it more suitable for applications in seismic contexts. The experimental results obtained by Hawileh et al. [18] were used to train and test an Artificial Neural Network (ANN) model [22]. Eight samples were used to test the accuracy of the ANN model in predicting the fatigue life of BS460B and B550B bars. The results provided by the ANN were comparable with the experimental results. Massone and Herrera [23] investigated the residual fatigue life of reinforcing bars recovered from wall boundaries zones of a building damaged during the 2010 Chile earthquake. The residual fatigue life was obtained by comparing the fatigue life of damaged (buckled), and undamaged (without buckling) samples obtained from the same reinforcing bar extracted from wall boundaries zones, against the fatigue life of "unaltered" steel reinforcing bars of similar properties (Grade A630S, $f_{y}=420 \mathrm{MPa}$ ) obtained from a different source. Experimental results showed that the fatigue life of the reinforcing bars extracted from the building (with and without damage) was on average $40 \%$ less than the fatigue life of the unaltered reinforcing bars. The authors concluded suggesting that, in the case of building repair, the entire reinforcing bars extracted from wall boundary zones should be replaced, and not limiting the replacement to the observed buckled length. Bakkar et al. [24] investigated the LCF behaviour of thermomechanically treated (TMT) Fe 500 and Fe500D grade rebars. The steel samples were subjected to strain-controlled constant amplitude cyclic histories. Results showed that both Fe500 and Fe500D TMT rebars were subjected to cyclic softening until failure. This behaviour is expected in materials with tensile to yield strength ratio smaller than 1.2. The CoffinMason and Basquin relationships predicted the fatigue life of both grades. In the case of grade Fe 500D, strain energy-based models were also successfully employed. Finally, in all the samples fatigue cracks initiated at the transverse rib root and then propagated along the rim region, following the brittle martensite phase [14, 24]. High- and low-cycle fatigue of microalloyed and TMT rebars was investigated by Paul et al. [25]. The experimental results showed that microalloyed rebars have a better fatigue performance compared to TMT bars. Also, numerical simulations confirmed that stress concentration and high-stress triaxiality take place at the root of the transverse ribs causing crack initiation at that location [25].

\section{Research objective}

Studies have shown that the residual fatigue life of steel reinforcing is reduced due to the cumulative damage caused by earthquake-induced cyclic strain history [23]. However, the residual fatigue life may be further reduced due to strain ageing. To the authors' knowledge, no publications are available on the effects of strain ageing on the low- and high-cycle fatigue life of steel reinforcing bars. The objective of this research is to investigate the effects of strain ageing on the residual low-cycle fatigue life of low-carbon steel reinforcing bars prone to this phenomenon. The 
reduction in the residual fatigue life of New Zealand Grade $300 \mathrm{E}$ steel is quantified.

\section{Material and methods}

Standard Grade 300E steel was received from a New Zealand local manufacturer, Pacific Steel Ltd, in 12-mm diameter reinforcing bars. The rebars were manufactured from scrap metals, melted in an electric arc furnace (EAC) at $1600{ }^{\circ} \mathrm{C}$. Alloy agents (e.g. carbon, manganese, etc.) were added and the product was hot-rolled at $1000{ }^{\circ} \mathrm{C}-1100{ }^{\circ} \mathrm{C}$. The $12-\mathrm{mm}$ rebars are usually produced in coils and then straightened. The chemical composition of the steel received is summarised in Table 1.

The average mechanical properties were obtained by testing monotonically three steel samples. The lower yield stress $\left[f_{y}\right]$ was $314 \mathrm{MPa}$, the ultimate tensile stress $\left[f_{u}\right]$ was $447 \mathrm{MPa}$, and the ultimate strain $\left[\varepsilon_{u}\right]$ was $19.3 \%$. The stress-strain curves of the three monotonic samples showed that the reinforcing bars do not manifest the Lüders strains typical of lowcarbon steels (Fig. 4). Therefore, the yield stress was obtained as the $0.2 \%$ proof stress as per AS1391-2007 [26].

\subsection{Benchmark fatigue-life test procedure}

Steel samples were cyclically tested at constant strain amplitude maintaining the mean strain equal to zero (completely-reversed cycles, $R=\frac{\varepsilon_{\min }}{\varepsilon_{\max }}=-1$ ). In order to subject the samples to a constant-strain amplitude, tests were conducted in strain control.

The test set-up was developed accounting for the laboratory constraints: the capability of the testing machine, a servo-hydraulic MTS 810 system with 100 $\mathrm{kN}$ load capacity, the size of the vee-wedge devices for gripping the steel specimens, and the extensometer specifications (25 mm gauge length, 50\% travel in tension and $10 \%$ in compression). The most suitable bar diameter size was $12 \mathrm{~mm}$.
Strain-controlled tests are routine practice in material testing in the case of machined specimens that are designed to avoid buckling. In such experiments, specimens are machined to either a smooth cylinder (uniform-gauge specimen) or an hour-glass shape and the surface finish is often polished [27]. The specimen geometry and the surface finish allow the strain device to be attached to the specimen, usually an extensometer, to measure the strain and control the actuator motion with a very small risk of slippage. The ratio between specimen gauge length and cross-sectional area is sufficiently small to avoid buckling [10]. However, since this research aimed to investigate the low-cycle fatigue life of steel reinforcement typically used in concrete elements, the original geometry of the rebars was maintained and buckling was not prevented. The testing length adopted was $72 \mathrm{~mm}(L)$, which corresponds to six bar-diameter $(d)$. The ratio $s=d / L$ equal to 6 was selected based on the experimental test conducted by Mander et al. [1]. They investigated the effects of the supported length and diameter ratio on the inelastic buckling by carrying out compressive tests for $s$ equal to 6,8 and 9. It was observed that for specimens with $s=6$, the shape of the compressive and tensile stress-strain curves up to the ultimate tensile stress were similar except for the fact that the ultimate tensile strength in compression was reached at a lower strain level. On the other hand, an increase in $s$ caused a significant reduction of the ultimate stress and ultimate strain in compression compared to the same properties in tension. This stress loss was accompanied by a significant bar buckling.

Preliminary strain-controlled cyclic tests were conducted on unmachined rebars with the extensometer responsible for governing the tensile machine attached to the specimen under testing. These preliminary tests showed machine instability due to buckling of the specimens at larger strain amplitudes. Since the aforementioned testing set-up was not viable, an alternative method to conduct strain-controlled fatigue tests was proposed. Henceforth, this method will be referred to as the "indirect method". Two steel

Table 1 Chemical composition data (wt.\%) from Mill Certification Sheet

\begin{tabular}{|c|c|c|c|c|c|c|c|c|c|c|c|}
\hline $\mathrm{C}$ & $\mathrm{Mn}$ & $\mathrm{Si}$ & $\mathrm{S}$ & $\mathrm{P}$ & $\mathrm{Ni}$ & $\mathrm{Cr}$ & Mo & $\mathrm{Cu}$ & $\mathrm{Sn}$ & V & $\mathrm{C}_{\mathrm{eq}}$ \\
\hline 0.10 & 0.50 & 0.14 & 0.013 & 0.012 & 0.02 & 0.03 & 0.000 & 0.01 & 0.003 & 0.040 & 0.20 \\
\hline
\end{tabular}


brackets welded to two round polished steel bars were fixed to the top and bottom heads of the MTS 810 system. The extensometer, an adjustable gauge length extensometer whose gauge length was set to $25 \mathrm{~mm}$ (Fig. 2), controlling the MTS machine was attached to the top and bottom external bars.

An extensometer calibration was required in order to fully employ the indirect method [28]. Two extensometers were used: one was attached to the steel reinforcing bar and another ("external extensometer") to the external steel top and bottom rods (see Fig. 2). Three monotonic tensile tests, with both extensometers attached, were conducted in order to calibrate the relationship between the "real" strain in the material $(\varepsilon)$, and the strain measured by the external extensometer $(v)$.

The calibration sample using the following procedure:

1. The elastic modulus of the material $(E)$ was measured from the actual stress-strain curve $(\sigma-$ $\varepsilon)$; an elastic constant $(K)$ was obtained from the stress-"displacement" curve $(\sigma-v)$ derived using the external extensometer;

2. The plastic strain $\varepsilon_{p}=\varepsilon-\frac{\sigma}{E}$ and the "plastic displacement" $v_{p}=v-\frac{\sigma}{K}$ were calculated;

3. $\varepsilon_{p}$ and $v_{\mathrm{p}}$ were plotted on $\log -\log$ coordinates (Fig. 3) and a power equation relationship was obtained:

$\varepsilon_{p}=0.3395 v_{p}^{1.0885}$

4. Once the strain limits $(\varepsilon)$ that will be used in the test were selected, the Eq. (3) was used to determine $v$, the "displacement" limits to set to the external extensometer.

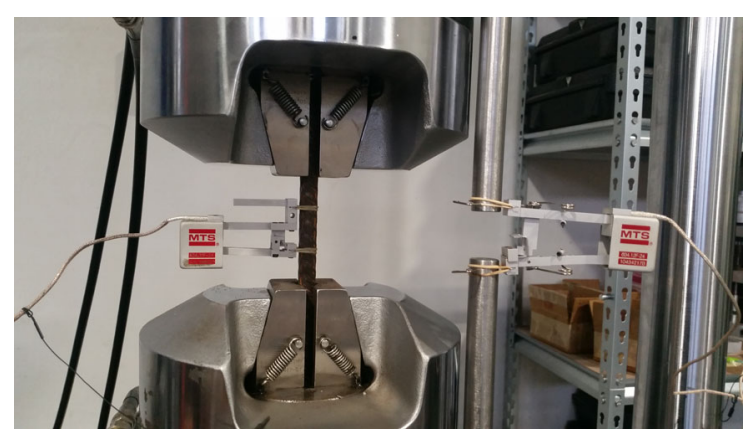

Fig. 2 Test set-up for the initial calibration test

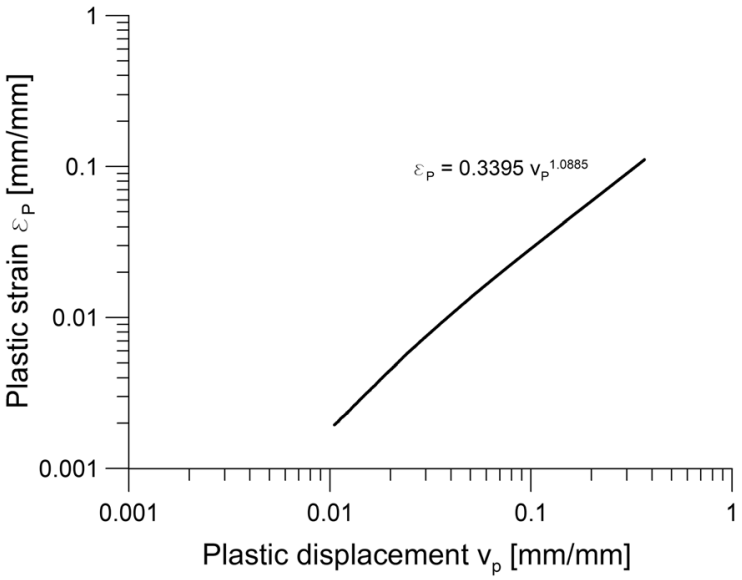

Fig. 3 Plastic strain $\varepsilon_{P}$ versus plastic displacement vp curve on $\log -\log$ coordinates

The calibration process was applied on a monotonic tensile test to verify the method. Figure 4 compares the actual stress-strain curve with the "calibrated" stress-strain curve obtained using the relationship derived. It demonstrates that the calibrated curve approximates the actual one reasonably well.

Because of the limited travel length of the extensometer in compression, the maximum strain amplitude selected was 3\%. A sinusoidal wave type was selected. The frequency decreased proportionally with the increase in strain amplitude in order to avoid heating of the steel specimens caused by the dissipation of the plastic strain energy.

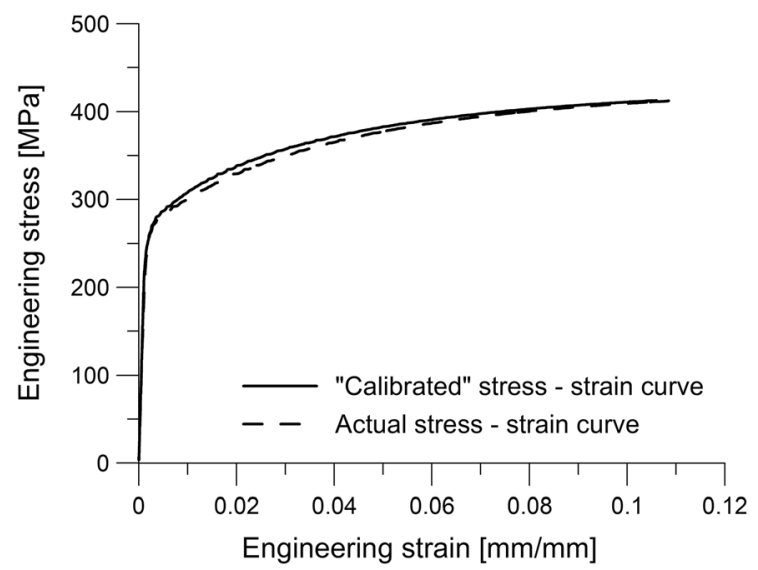

Fig. 4 "Calibrated" versus actual stress-strain curves 


\subsection{Strain Vickers hardness indentations ageing effects testing procedure}

In order to quantify any reduction in fatigue life of the rebars attributed to strain ageing, two experiments followed the benchmark experiment discussed previously. In the first experiment, new specimens were initially cyclically loaded up to one-third (33\%) of their benchmark fatigue life (pre-cycle phase). In the second experiment, the number of pre-cycles was equal to two-thirds $(66 \%)$ of their benchmark fatigue life. Then, the "pre-cycled" samples were aged for $4 \mathrm{~h}$ at $100^{\circ} \mathrm{C}$ (boiling water). This is equivalent to 1 -year ageing at $15{ }^{\circ} \mathrm{C}$ as demonstrated by Hundy [29] and Loporcaro et al. [5]. In the last phase, the steel samples were cyclically tested at the same strain amplitudes of the pre-cycle phase until fracture. The testing length was the same as in the pre-cycled phase. Six steel samples were tested in both the first and the second experiments.

\section{Results and discussions}

\subsection{Microstructure characterization}

Optical microscopic investigations conducted on nital-etched cross-sections of a rebar sample showed a uniform microstructure throughout, consisting of grains of ferrite (white regions) and pearlite colonies (dark regions) as represented in Fig. 5a, b. Vickers hardness indentations were carried out on the rebar cross-section to investigate any residual stress caused by straightening the coiled $12-\mathrm{mm}$ diameter rebars. Results showed a non-uniform hardness distribution. The Vickers hardness in the rim region was higher than the hardness in the core region (see Fig. 6) which is an indication of the presence of residual stresses in the outer region of the bar caused by the straightening process of the coiled bars.

\subsection{Benchmark number of cycles to failure}

A summary of the benchmark test results alongside the strain amplitude and frequency adopted are presented in Table 2 .

For the strain levels investigated, Grade $300 \mathrm{E}$ exhibited cycle-dependent hardening, where the stress increases with the number of cycles until it reached a stable hysteresis loop. Cycling strain hardening is expected in materials with ultimate tensile to yield strength ratio larger than 1.4 [30]. The calculated ultimate tensile and yield strength ratio for the tested rebars is 1.42 . The stress increase occurred only after the first cycle, then the stress remained approximately constant until cracking started. This behaviour can be observed in Fig. 7, where the normalised stress at reversal $\left(f_{i} / f_{0}\right)$ is plotted against the number of cycles; $f_{i}$ is the stress at the reversal point during the $i_{\text {th }}$ generic cycle, while $f_{0}$ is the stress at the first reversal. The stress at reversal differs in tension and compression. The graph shows how the normalised stress increased
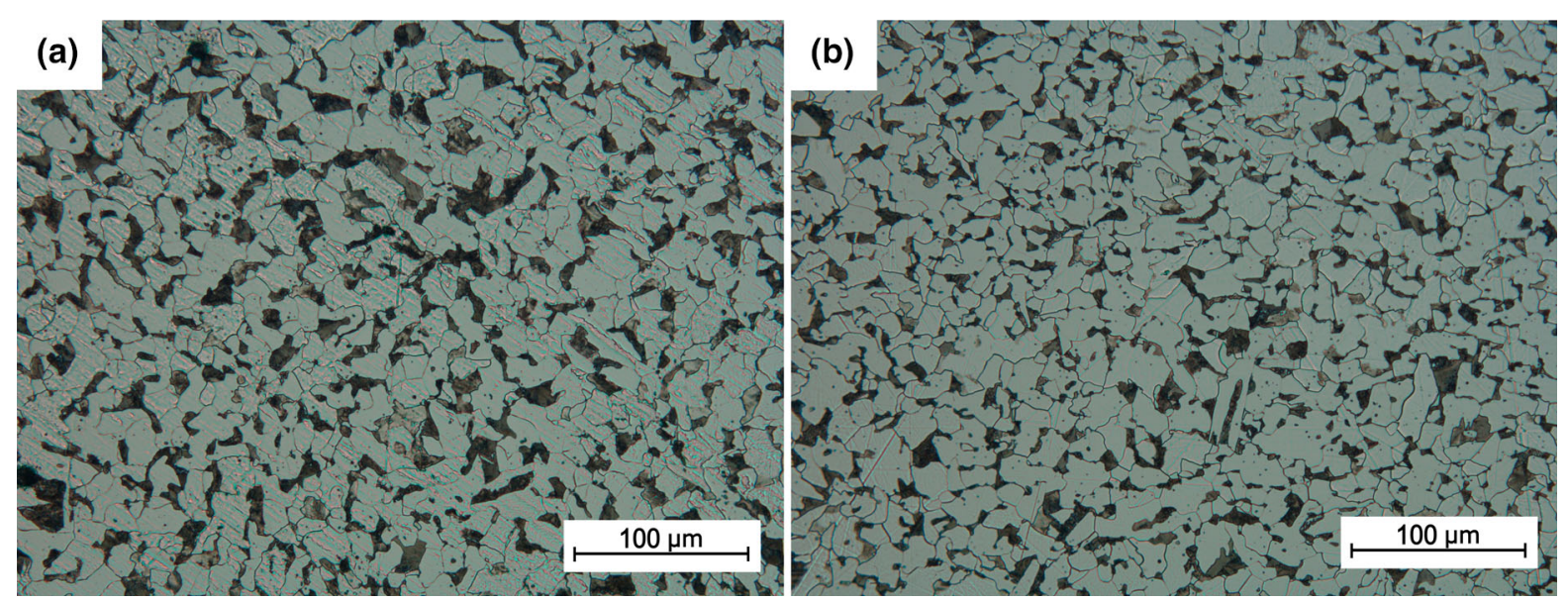

Fig. 5 Photomicrograph showing the ferrite-perlite microstructure of $\mathbf{a}$ the core region and $\mathbf{b}$ the rim region of the cross-section of a Grade 300E rebar sample 


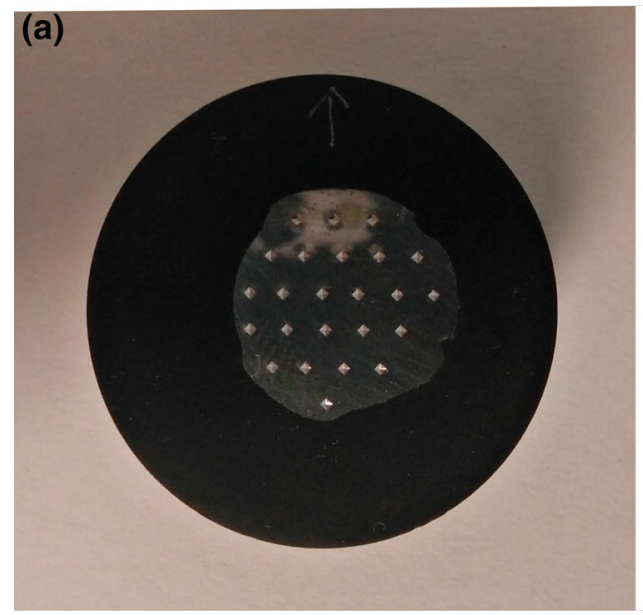

(b)

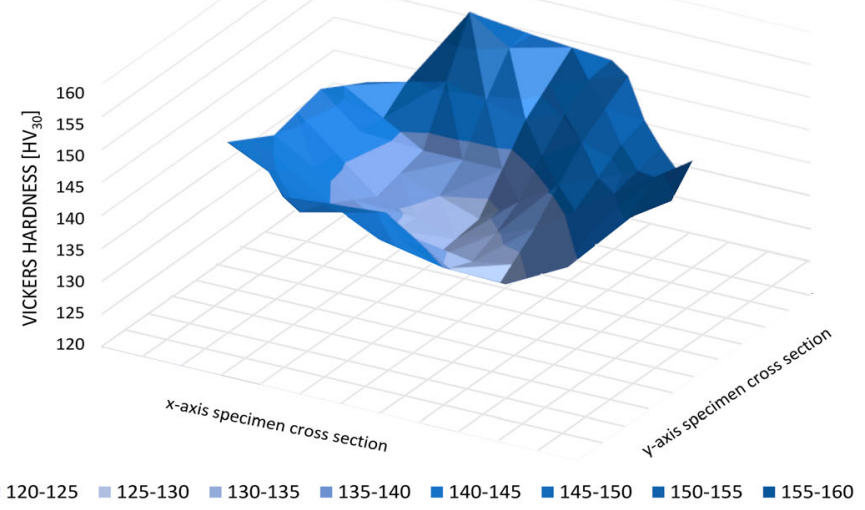

Fig. 6 a Vickers hardness indentations on the cross-section of a rebar sample and bVickers hardness results plotted on a 3-axis graph

Table 2 LCF parameters adopted in the testing and results

\begin{tabular}{lllll}
\hline Specimen number & Total strain amplitude $\left(\varepsilon_{a}\right)[\%]$ & Plastic strain amplitude $\left(\varepsilon_{a p}\right)[\%]$ & Frequency $[\mathrm{Hz}]$ & No. cycles to failure $\left(N_{f}\right)$ \\
\hline 1 & \pm 0.78 & \pm 0.61 & 0.12 & 125 \\
2 & \pm 0.78 & \pm 0.62 & 0.12 & 130 \\
3 & \pm 0.83 & \pm 0.67 & 0.12 & 98 \\
4 & \pm 1.07 & \pm 0.89 & 0.11 & 34 \\
5 & \pm 1.40 & \pm 1.21 & 0.09 & 32 \\
6 & \pm 1.40 & \pm 1.21 & 0.09 & 14 \\
7 & \pm 1.78 & \pm 1.56 & 0.06 & 16 \\
8 & \pm 1.79 & \pm 1.60 & 0.06 & 13 \\
9 & \pm 1.79 & \pm 1.60 & 0.06 & 6 \\
10 & \pm 2.71 & \pm 2.50 & 0.04 & 6 \\
11 & \pm 2.72 & \pm 2.52 & 0.04 & 7 \\
\hline
\end{tabular}

after the first cycle and then remained constant before dropping significantly before failure. The normalised stress at reversal vs. cycle number curves was also be used for determining the specimen's strain life. As observed in the previous studies, an inflection point ("cusp formation") exists in the compressive region of the cyclic stress-strain curve (see Fig. 8) [1, 17, 18]. This phenomenon occurred approximately toward the end of the specimen fatigue life when cracking initiated.

In order to determine the fatigue life to failure, two methods were used depending on the strain amplitude to which the specimens were subjected. For specimens cycled at amplitudes below $2 \%$, the normalised stress at reversal $\left(f_{i} / f_{0}\right)$ versus the number of cycles curves were used (Fig. 7). The number of cycles to failure was obtained by counting the cycles required to reach a ratio $f_{i} / f_{o}$ (in tension) equal to 1 . For specimens subjected to strain amplitudes above $2 \%$, the number of cycles to failure was obtained by counting the cycles when the first crack was visually detected. Cracking started at the base of a steel deformation (rib) on the bar surface, as these locations represented stress concentration points. When the specimens were removed from the machine, after a careful inspection more than one crack was often observed (Fig. 9). Fatigue crack initiation at the rib root has been reported in TMT and micro-alloyed rebars as well as in 


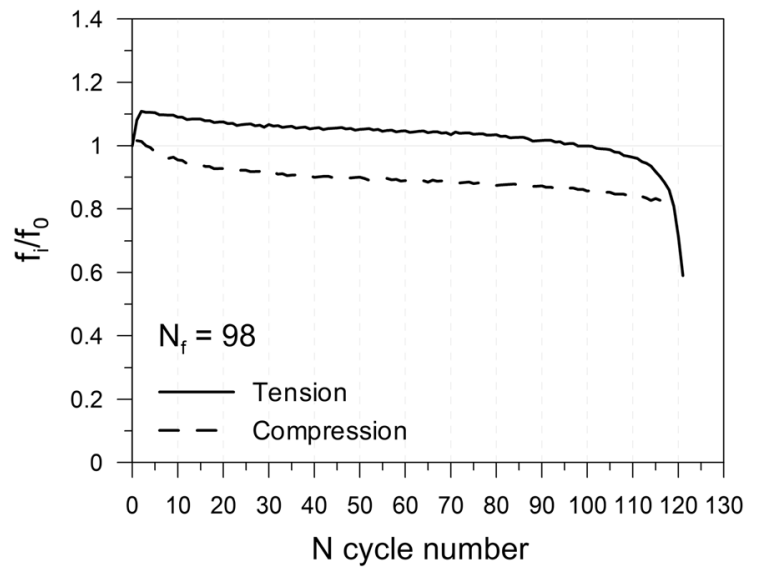

Fig. 7 Normalised stress at reversal versus the number of cycles for Sample 03

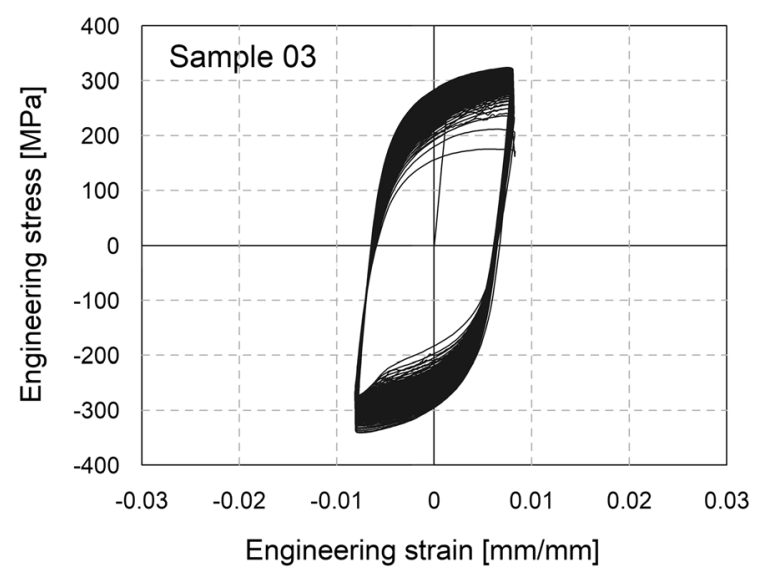

Fig. 8 Cyclic stress-strain curve of sample 03

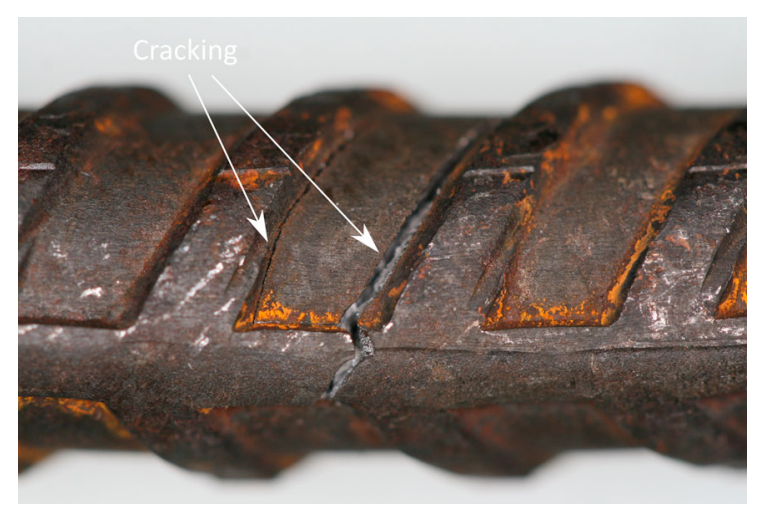

Fig. 9 Cracks formed at the base of the steel ribs

numerical investigations [14, 24, 25]. Specimens' fatigue lives are summarised in Table 2.
5.3 Fatigue life prediction of the virgin rebars

The number of cycles to failure derived from the benchmark test reported in Table 2 were used to fit the combined Basquin and Coffin-Mason relationship:

$\varepsilon_{a}=0.0025\left(2 N_{f}\right)^{-0.076}+0.080\left(2 N_{f}\right)^{-0.464}$

The fitting curve described by equation (4) is plotted for the life range $\mathrm{N}_{\mathrm{f}}=6$ to 130 in Fig. 10a. Since LCF failures are governed by large plastic deformation, the total strain amplitude versus fatiguelife curve is very well approximated by the plastic strain curve. The relationship obtained by considering only the plastic contribution is:

$\varepsilon_{p a}=0.080\left(2 N_{f}\right)^{-0.464}$

The $R^{2}$ value was 0.989 .

Experimental results were also used to fit the Koh and Stephens model:

$\varepsilon_{a}=0.0755\left(2 N_{f}\right)^{-0.412}$

The coefficient $M$ and exponent $\mathrm{m}$ were derived by performing a linear regression analysis. The calculated $R^{2}$ value was 0.990 . Relationship (6) is plotted in Fig. 10b.

The Coffin-Manson (only plastic strain amplitude) and the Koh-Stephens models provided similar results. The coefficient of determination $R^{2}$ suggested a good correlation between the experimental results and the fatigue-life predictions. This first part of the experimental testing was conducted to provide the benchmark LCF life of Grade 300E steel. In the next section, the results obtained are used as a benchmark to quantify the change in the fatigue life caused by strain ageing.

\subsection{Strain ageing effects on total- and residual- fatigue life}

The total fatigue-life results obtained from the tests on the aged and unaged specimens are compared in Tables 3 and 4 . The comparison shows that for samples pre-cycled to $33 \%$ of the benchmark fatigue life, the total fatigue loss that can be attributed to strain ageing is on average around $30 \%$, ranging from 14 to $50 \%$. On the other hand, the average total fatigue loss for specimens pre-cycled to $66 \%$ of the benchmark fatigue life is approximately $19 \%$ and ranged between 

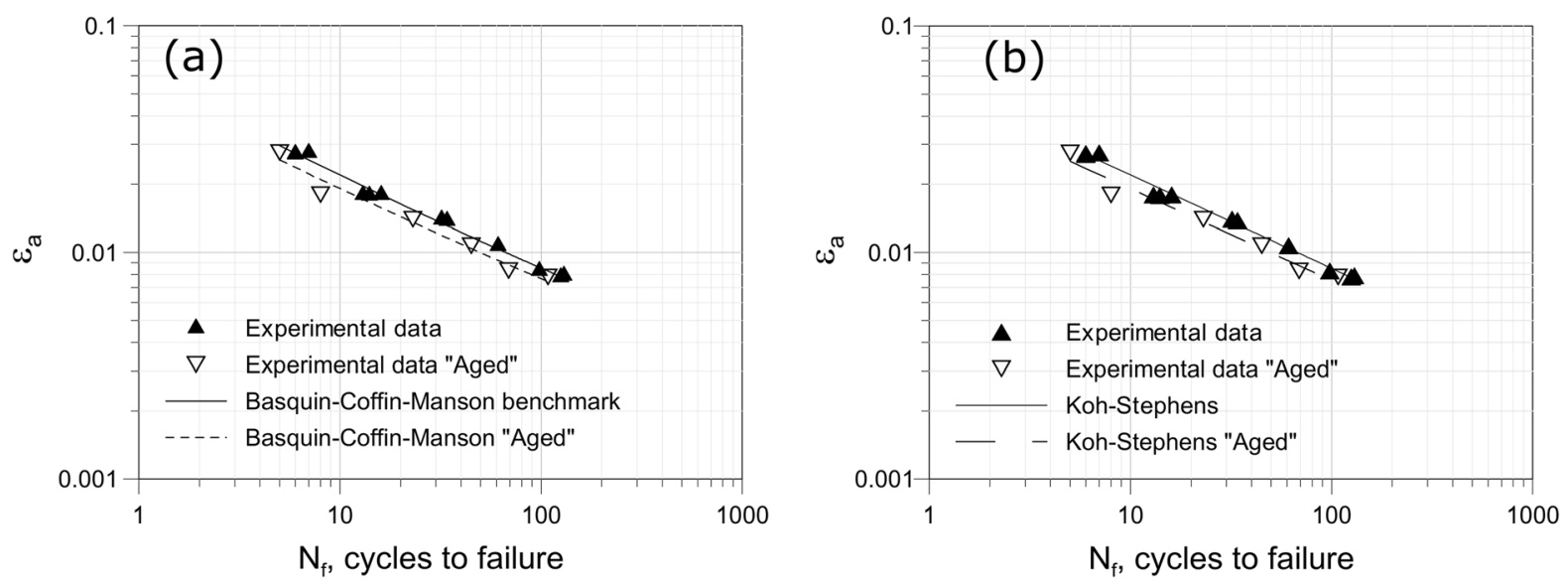

Fig. 10 a Basquin-Coffin-Manson model and b Koh-Stephens model applied to fatigue life results of unaged and aged samples (33\% pre-cycle)

Table 3 LCF parameters adopted in the test and results for the $33 \%$ pre-cycled and aged samples

\begin{tabular}{llllll}
\hline $\begin{array}{l}\text { Strain } \\
\text { amplitude [\%] }\end{array}$ & $\begin{array}{l}\text { Benchmark } \\
\left(N_{f}\right)\end{array}$ & $\begin{array}{l}\text { Number of cycles } \\
\text { prior ageing }\end{array}$ & $\begin{array}{l}\text { Number of cycles } \\
\text { after ageing }\end{array}$ & $\begin{array}{l}\text { Total } N_{f} \text { for pre-cycled and } \\
\text { aged specimens }\end{array}$ & $\begin{array}{l}\text { Total fatigue life } \\
\text { loss [\%] }\end{array}$ \\
\hline 0.78 & 125 & 42 & 66 & 108 & 14 \\
0.83 & 98 & 32 & 37 & 69 & 30 \\
1.07 & 61 & 20 & 25 & 45 & 26 \\
1.40 & 32 & 11 & 12 & 23 & 28 \\
1.79 & 16 & 5 & 3 & 8 & 50 \\
2.75 & 7 & 2 & 3 & 5 & 29 \\
\hline
\end{tabular}

Table 4 LCF parameters adopted in the test and results for $66 \%$ pre-cycled and aged samples

\begin{tabular}{llllcl}
\hline $\begin{array}{l}\text { Strain } \\
\text { amplitude [\%] }\end{array}$ & $\begin{array}{l}\text { Benchmark } \\
\left(N_{f}\right)\end{array}$ & $\begin{array}{l}\text { Number of cycles } \\
\text { prior ageing }\end{array}$ & $\begin{array}{l}\text { Number of cycles } \\
\text { after ageing }\end{array}$ & $\begin{array}{l}\text { Total } N_{f} \text { for pre-cycled and } \\
\text { aged specimens }\end{array}$ & $\begin{array}{l}\text { Total fatigue life } \\
\text { loss [\%] }\end{array}$ \\
\hline 0.78 & 125 & 84 & 18 & 102 & 18 \\
0.83 & 98 & 65 & 9 & 74 & 24 \\
1.07 & 61 & 40 & 8 & 48 & 21 \\
1.40 & 32 & 21 & 6 & 27 & 16 \\
1.79 & 16 & 10 & 3 & 13 & 19 \\
2.75 & 7 & 4 & 2 & 6 & 14 \\
\hline
\end{tabular}

16 and $24 \%$. Although the effects of strain ageing may appear more pronounced in the case of samples precycled to $33 \%$, it must be noted that for the $66 \%$ precycled specimens most of the fatigue life was already exhausted in the unaged condition.

As per the benchmark experiment, the BasquinCoffin-Manson and Koh-Stephens models were used to fit the experimental data obtained from the specimens pre-cycled at $33 \%$ and $66 \%$ of the original fatigue life, subsequently aged and cyclically tested to failure (Figs. 10 and 11). Regression analyses were performed to determine the coefficients $\sigma_{f}{ }_{f}, b, \varepsilon_{f}, c$ for the Basquin-Coffin-Manson model, and $M$ and $m$ for 

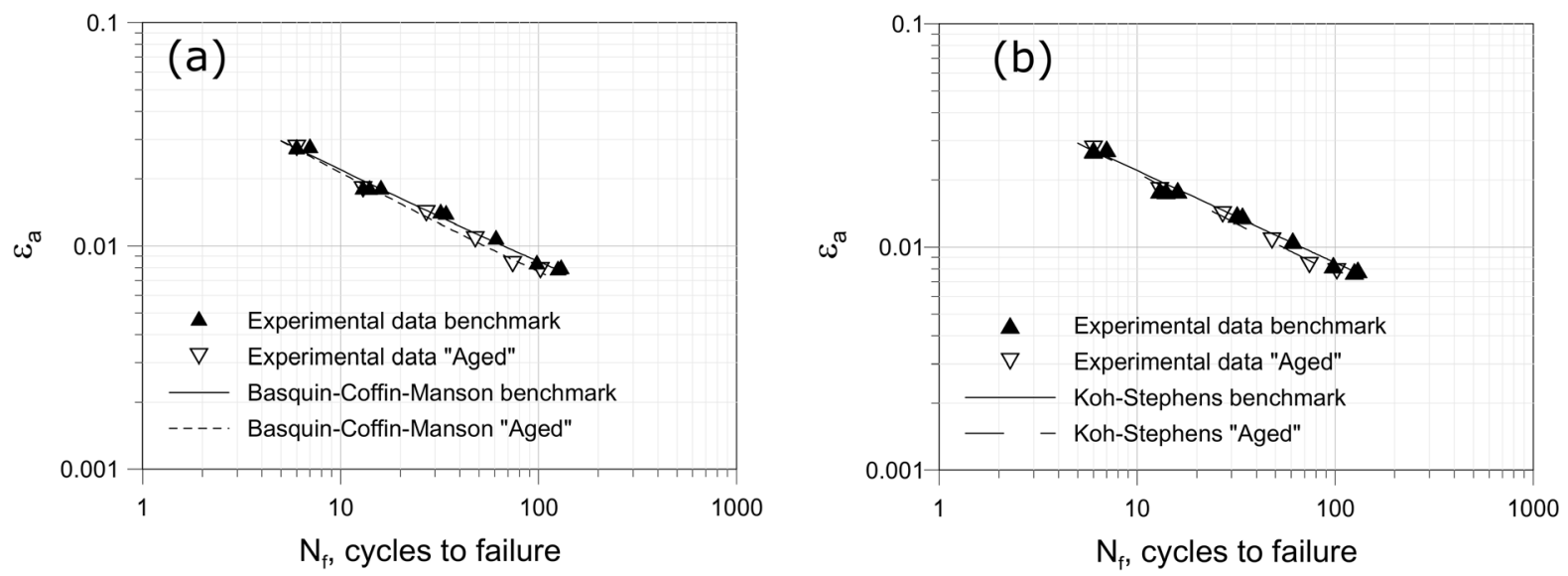

Fig. 11 a Baquin-Coffin-Manson model and b Koh-Stephens model applied to fatigue life results of unaged and aged samples (66\% pre-cycle)

Table 5 Summary of the constants and coefficients of the Baquin-Coffin-Manson and Koh-Stephens models

\begin{tabular}{lllllllll}
\hline Models & \multicolumn{2}{l}{ Basquin- Coffin- Manson } & \multicolumn{2}{l}{ Koh-Stephens } & & & & \\
\cline { 2 - 8 } Constants & $\sigma_{f}^{\prime}$ & $b$ & $\varepsilon_{f}$ & $c$ & $R^{2}$ & $M$ & $m$ & $R^{2}$ \\
\hline Benchmark test & 0.0025 & -0.076 & 0.080 & -0.464 & 0.989 & 0.075 & -0.412 & 0.990 \\
$33 \%$ precycled test & 0.0025 & -0.076 & 0.067 & -0.456 & 0.971 & 0.064 & -0.404 & 0.967 \\
$66 \%$ precycled test & 0.0026 & -0.085 & 0.088 & -0.507 & 0.994 & 0.082 & -0.449 & 0.993 \\
\hline
\end{tabular}

the Koh-Stephens model. These are summarised in Table 5.

Analysis of the results summarized in Table 5 reveal that the fatigue strength coefficient $\left(\sigma^{\prime}{ }_{f}\right)$ and the fatigue strength exponent $(b)$ obtained from the benchmark and the $33 \%$ pre-cycle tests are the same. This may indicate that for the strain-amplitude range under investigation, strain ageing does not affect the elastic range portion described by the Baquin relationship.

The fatigue ductility exponents $c$, which represents the slope of the plastic strain amplitude versus the number of reversals in a log-log scale [Fig. 10a], are similar to the benchmark ( 0.464$)$ and $33 \%$ pre-strain ( 0.456$)$ tests. On the other hand, the fatigue ductility coefficients $\varepsilon_{f}$, which represents the intercept of the same diagram, are different. In other words, the strainlife curves for the benchmark and the $33 \%$ precycled tests are approximately parallel as shown in Fig. 10a. Therefore, for the strain amplitudes under investigation, if one-third of the fatigue life of Grade 300E steel has been exhausted, a reduction of fatigue life is expected due to strain ageing. It can be concluded that strain ageing consistently reduces the fatigue life of specimens. The fatigue life of the strain aged samples can be estimated with the proposed Baquin-CoffinManson relationship. Similar considerations can be made when the costants $M$ and $m$ relative to the KohStephens models are compared for the benchmark and $33 \%$ pre-cycled tests [see Table 5 and Fig. 10b].

When comparing the strain-life curves relative to the benchmark and the $66 \%$ precycle experiments (Fig. 11), different considerations can be made. At large strain amplitudes, the two curves approximately coincide, this is because the fatigue life of the rebars is almost exhausted in the pre-cycle phase. The benchmark and "aged" curves intersect at strain amplitudes of approximately $2.5 \%$. However, as the strain amplitude decreases and the number of cycles to failure increases, the two curves start to diverge and the effect of strain ageing on the fatigue life of the rebars becomes more evident. Therefore, results suggest that strain ageing affects the fatigue life of samples subjected to small strain amplitudes in a range 
between yielding and approximately $1-1.5 \%$. For example, the reduction in fatigue life of the rebars subjected to strain amplitudes below 1\% was 23-24 cycles. For strain amplitudes larger than $1.5 \%$, when two-third of the life was exhausted, the effects of strain ageing may be not relevant since very few cycles are remaining before failure. For example, the reduction in fatigue life of the rebars subjected to strain amplitudes above $1.4 \%$ was below 5 cycles.

The residual fatigue life refers to the number of cycles that a bar may experience after a previous cycling loading. The loss in residual fatigue life was calculated by subtracting the observed "aged" fatigue life from the unaged fatigue life. The unaged residual fatigue life was determined as the difference between the benchmark fatigue life and the number of cycles applied in the pre-cycle phase (before ageing). In Table 6, the loss in residual fatigue life is expressed as the number of cycles lost due to strain ageing (the negative sign means that the number of cycles after ageing is less than the expected unaged fatigue life) and as a percentage. The residual fatigue-life loss for the specimens pre-cycles to $33 \%$ was on average $43 \%$ (of the expected unaged residual fatigue life) and ranged from a minimum of $20 \%$ ( 17 cycles at $0.78 \%$ strain) to a maximum of $70 \%$ (8 cycles at $1.79 \%$ strain). The residual fatigue life loss for the aged specimens pre-cycled to $66 \%$ was more dramatic: it varied between $33 \%$ ( 1 cycle at $2.75 \%$ strain) and $73 \%$ (24 cycles at $0.83 \%$ strain), with an average loss of $53 \%$. As a result, the larger the amount of pre-cycling, the higher is the residual fatigue-life loss, if the ageing time does not vary. However, also in the case of the residual fatigue life, in two-third of the fatigue life is exhausted in the precycled phase, the effects of strain ageing at strain amplitudes above $1.5 \%$ may be ignored and deem the bar failed.

\section{Conclusions}

In this paper, the effects of strain ageing on the lowcycle fatigue life of New Zealand Grade 300E steel reinforcement were investigated experimentally. Unmachined 12-mm diameter rebars were tested in strain-control to tension-compression loading employing an "indirect method". A benchmark strain-life curve was obtained by subjecting the steel specimens to completely reversed cycles with strain amplitudes ranging from 0.78 to $2.75 \%$. To quantify the effects of strain ageing, two sets of experiments were conducted. Steel specimens were first cyclically tested at multiple strain amplitudes up to $33 \%$ and $66 \%$ of the benchmark fatigue life; then strain aged for four hours at $100{ }^{\circ} \mathrm{C}$ (equivalent to one year at $15{ }^{\circ} \mathrm{C}$ ); and, finally cyclically re-tested at the same strain amplitudes until failure. The following conclusions are drawn:

- Strain ageing causes a reduction in the total fatigue life when compared with unaged benchmark fatigue.

- The total fatigue life of the aged Grade $300 \mathrm{E}$ steel can be estimated with the Baquin-Coffin-Manson and Koh-Stephens models using the material constants developed in this research.

- The reduction in residual fatigue life ranged from a minimum of $20 \%$ to a maximum of $73 \%$ of the expected residual fatigue life. The effects of strain ageing on the residual fatigue life were more

Table 6 Loss in residual fatigue life for aged samples pre-cycled to $33 \%$ and $66 \%$ of the initial fatigue life

\begin{tabular}{lllll}
\hline Strain amplitude & $\begin{array}{l}\text { Loss in residual fatigue life for 33\% } \\
\text { pre-cycled and aged specimens } \\
\text { No of cycles }\end{array}$ & \multicolumn{4}{l}{ Loss in residual fatigue life for 66\% pre-cycled and aged specimens [\%] } \\
\cline { 3 - 5 } & {$[\%]$} & No. of cycles & {$[\%]$} \\
\hline 0.78 & -17 & 20.5 & -23 & 56.1 \\
0.83 & -29 & 43.9 & -24 & 72.7 \\
1.07 & -16 & 39.0 & -13 & 61.9 \\
1.40 & -9 & 42.9 & -5 & 45.5 \\
1.79 & -8 & 72.7 & -3 & 50.0 \\
2.75 & -2 & 40.0 & -1 & 33.3 \\
\hline
\end{tabular}


pronounced on the samples precycled to $66 \%$ of the benchmark fatigue life.

- The reduction in LCF life is substantial, therefore, it should be taken into account in the assessment of the residual capacity of steel reinforcing bars.

Further experimental testing is suggested to estimate the fatigue life of samples subjected to large strain amplitudes $(>2.75 \%)$ and a small number of cycles before ageing and small strain amplitudes $(<0.78 \%)$ and a large number of cycles before ageing.

Acknowledgements The authors are grateful to the Natural Hazards Research Platform and MBIE Building System Performance Branch for financial support through the SAFER Structures Research Project, Pacific Steel and Bruce Roberts for providing the steel used in this research. The authors also acknowledge the helpful discussions with Emeritus Professor Norman Dowling from the Virginia Tech and Emeritus Professor Les Erasmus from the University of Canterbury.

Funding Open Access funding enabled and organized by CAUL and its Member Institutions. This study was funded by Natural Hazards Research Platform, New Zealand(SAFER buildings project) and MBIE Building System Performance Branch (New Zealand).

\section{Declarations}

Conflict of interest The authors declare that they have no conflict of interest.

Open Access This article is licensed under a Creative Commons Attribution 4.0 International License, which permits use, sharing, adaptation, distribution and reproduction in any medium or format, as long as you give appropriate credit to the original author(s) and the source, provide a link to the Creative Commons licence, and indicate if changes were made. The images or other third party material in this article are included in the article's Creative Commons licence, unless indicated otherwise in a credit line to the material. If material is not included in the article's Creative Commons licence and your intended use is not permitted by statutory regulation or exceeds the permitted use, you will need to obtain permission directly from the copyright holder. To view a copy of this licence, visit http://creativecommons.org/licenses/by/4.0/.

\section{References}

1. Mander J, Panthaki F, Kasalanati A (1994) Low-cycle fatigue behavior of reinforcing steel. J Mater Civ Eng 6(4):453-468

2. El-Bahy A, Kunnath S, Stone WC, Taylor AW (1999a) Cumulative seismic damage of circular bridge columns: Benchmark and low-cycle fatigue tests. ACI Struct J, 96(4)
3. El-Bahy A, Kunnath S, Stone W, Taylor A (1999b) Cumulative seismic damage of circular bridge columns: Variable amplitude tests. ACI Struct J, 96(5)

4. Palermo A, Liu R, Rais A, McHaffie B, Andisheh K, Pampanin S, Gentile R, Nuzzo I, Granerio M, Loporcaro G, McGann C, Wotherspoon L (2017) Performance of road bridges during the 14 November 2016 Kaikoura earthquake. Bull N Z Soc Earthq Eng 50(2):253-270. https://doi.org/10. 5459/bnzsee.50.2.253-270

5. Loporcaro G, Pampanin S, Kral MV (2019) Long-term strain-ageing effects on low-carbon steel reinforcement. Constr Build Mater 228:116606. https://doi.org/10.1016/j. conbuildmat.2019.07.332

6. Cottrell AH, Bilby BA (1949) Dislocation theory of yielding and strain ageing of iron. Proc Phys Soc London Sect A 62(1):49

7. Erasmus, Pussegoda (1977) Strain age embrittlement of reinforcing steels. New Zealand Eng, 32(8)

8. Momtahan A, Dhakal R, Rieder A (2009) Effects of strainageing on New Zealand reinforcing steel bars. Bull New Zealand Soc Earthq Eng, 42(2)

9. Loporcaro G (2017) A least invasive method to estimate the residual strain capacity of steel reinforcement in earthquake-damaged buildings. University of Canterbury

10. Dowling NE (2013) Mechanical behavior of materials: engineering methods for deformation, fracture, and fatigue, 4th edn. Pearson, London

11. Basquin OH (1910) The exponential law of endurance tests. Am Soc Test Mater Proc 10:625-630

12. Coffin J (1954) A study of the effects of cyclic thermal stresses on a ductile metal. Trans Am Soc Mech Eng, 76

13. Manson (1953) Behavior of materials under conditions of thermal stress. NACA TN 2933

14. Bakkar MA, Kanrar B, Saha R, Das D (2020) High-strain low-cycle fatigue behavior of thermomechanically treated rebar. J Fail Anal Prev 20(3):1029-1037. https://doi.org/10. 1007/s11668-020-00911-z

15. Koh S, Stephens R (1991) Mean stress effects on low cycle fatigue for a high strength steel. Fatigue Fract Eng Mater Struct 14(4):413-428

16. Restrepo-Posada J, Dodd L, Park R, Cooke N (1994) Variables affecting cyclic behavior of reinforcing steel. J Struct Eng 120(11):3178-3196

17. Brown J, Kunnath SK (2004) Low-cycle fatigue failure of reinforcing steel bars. ACI Mater J, 101(6)

18. Hawileh AJ, Oudah F, Abdelrahman K (2010) Low-cycle fatigue life behaviour of BS 460B and BS B500B steel reinforcing bars. Fatigue Fract Eng Mater Struct 33(7):397-407. https://doi.org/10.1111/j.1460-2695.2010. 01452.x

19. Hawileh RA, Tabatabai H (2010) Evaluation of the lowcycle fatigue life in ASTM A706 and A615 Grade 60 steel reinforcing bars. J Mater Civ Eng 22(1):65-76. https://doi. org/10.1061/(ASCE)0899-1561(2010)22:1(65)

20. Hawileh RA, Tabatabai H, Abu-Obeidah A, Balloni J, Rahman A (2016) Evaluation of the low-cycle fatigue life in seven steel bar types. J Mater Civ Eng 28(5):06015015. https://doi.org/10.1061/(ASCE)MT.1943-5533.0001476

21. Abdalla J, Hawileh R, Oudah F, Abdelrahman K (2009) Energy-based prediction of low-cycle fatigue life of BS 
460B and BS B500B steel bars. Mater Des 30(10):4405-4413

22. Abdalla JA, Hawileh R (2011) Modeling and simulation of low-cycle fatigue life of steel reinforcing bars using artificial neural network. J Franklin Inst 348(7):1393-1403. https://doi.org/10.1016/j.jfranklin.2010.04.005

23. Massone LM, Herrera PA (2019) Experimental study of the residual fatigue life of reinforcement bars damaged by an earthquake. Mater Struct 52(3):61. https://doi.org/10.1617/ s11527-019-1361-x

24. Bakkar MA, Saha R, Das D (2020) Low cycle fatigue performance and failure analysis of reinforcing bar. Met Mater Int. https://doi.org/10.1007/s12540-020-00839-x

25. Paul SK, Rana PK, Das D, Chandra S, Kundu S (2014) High and low cycle fatigue performance comparison between micro-alloyed and TMT rebar. Constr Build Mater 54:170-179. https://doi.org/10.1016/j.conbuildmat.2013. 12.061
26. Standards Australia (2007) AS 1391-2007. Metallic materials-Tensile testing at ambient temperature. Sydney

27. ASTM (2012) E606/E606M. Standard Test Method for Strain-controlled Fatigue Testing. West Conshohocken, PA, United States

28. Dowling NE (1977) Crack growth during low cycle fatigue of smooth axial specimens. Stress strain and plastic deformation aspects of fatigue crack growth, ASTM STP 637:97-121

29. Hundy BB (1954) Accelerated Strain Ageing of Mild Steel. J Iron Steel Inst, 178

30. Hertzberg RW (1996) Deformation and fracture mechanics of engineering materials. Wiley, New York

Publisher's Note Springer Nature remains neutral with regard to jurisdictional claims in published maps and institutional affiliations. 